\title{
Negotiation Strategies of Myanmar Migrant Workers in the Sidhiphatra Cold Storage Factory, Songkhla Province
}

\author{
Phennapha Chandaenga, Jitprapat Saisopa ${ }^{a}$
}

\begin{abstract}
This paper studies the Myanmar migrant workers in Sidhiphatra Cold Storage Factory, Songkhla Province. This factory employs just over 2,000 Myanmar migrant workers. The authors study their "everyday life practices" as expressed in relationships among various groups, such as relationships between the Myanmar migrant workers and the factory, and the relationships between the Myanmar migrant workers and the Thai people of the surrounding communities. In analyzing these relationships and negotiations, the authors borrow the concept of "tactics of everyday life" from Michel de Certeau as a framework for analysis. The authors' analyses are based on in-depth interviews, non-participant observations, and focus-group discussions that collectively explored the tactics, in de Certeau's sense, that the Myanmar migrant workers used in negotiating their relationships with the factory and with the various communities in the area. The results indicate that Myanmar migrant workers negotiate their relationship with the factory by expressing themselves as selected workers, good workers, and being obedient to the factory's rules. The conflicts caused by Myanmar and Cambodian migrant workers are negotiated. Besides, Myanmar migrant workers also negotiate their relationship with the Thai people living in the surrounding communities. Their approach is showing that they are part of the communities by participating in the activities with the aim to gain acceptance of the Thai people in the surrounding communities.
\end{abstract}

\section{Keywords}

Myanmar migrant workers, negotiation, negotiation strategies

This paper reports the results of a study of Myanmar migrant workers who are working in the Sidhiphatra Cold Storage Factory (not its real name), which is located in Songkhla Province in southern Thailand. This factory processes canned tuna for overseas export. One reason why the authors chose this particular factory for a case study was because it employs just over 2,000 Myanmar migrant workers, all of whom come from the single country of Myanmar. Although the factory initially employed migrant workers from both Myanmar and Cambodia, at the time of the authors' study, all of the factory's migrant workers came from the single country of Myanmar. At the time of this study, factory was employing workers of no other nationality, except for a few hundred Thai workers from nearby communities. In this study, the authors are interested in how the workers have negotiated with the factory despite their position of relative weakness. The authors are interested in the

aWalailak University, Thailand

Correspondent Author:

Jitprapat Saisopa, Walailak University, Nakhon Si Thammarat 80161, Thailand 
forms those negotiations have taken, and the degree to which they have succeeded. In addition, the authors are interested in how the Myanmar migrant workers have negotiated with the Thai communities in the area. The factory is located in a rural area that has strong communities of Muslims who are strict in their religious practice, while the Myanmar migrant workers are mostly Buddhists, along with some Christians (many of the Myanmar migrant workers of Karen/Kayin ethnicity are Christians). The authors are therefore interested in the practices of everyday life that affect the relationships between the workers from Myanmar, who mostly practice Buddhism or Christianity, and the local communities, who are mostly Muslims, as the two groups interact and negotiate with each other.

Prior to beginning intensive fieldwork, the authors made general investigations about the factory, and discovered that the relationships between the Myanmar migrant workers and the local Muslim communities have included both conflicts and demonstrations of relative good will. Many interesting things have happened over the course of these relationships. Both groups had matters that they desired to negotiate in their lives and contact with each other, and ever since the factory began to be established in the year 2005, they have been contesting power relationships in order to gain benefits for their own groups. For example, the people of the surrounding Muslim communities proposed to the factory owners and to the local administrative bodies that the rules of their own Muslim community should be imposed on the workers who would be coming to live in the area. For example, they wanted the Myanmar migrant workers to be prohibited from leaving the factory premises, regardless of the reason. They also wanted to completely forbid the selling of whiskey and alcoholic beverages in their community. For their part, over the years, the Myanmar migrant workers have employed various negotiating tactics to be able to survive and work harmoniously with as little conflict as possible in their situation of newcomers in a community where most of the people were strictly following a different religion, and yet in a way that also increases their freedom. For example, by now, the Myanmar migrant workers have been able to renegotiate their conditions of life to the point that they are able to rent living quarters outside the factory. They are also able to freely drink alcoholic beverages and go frequently to pubs or liquor stores in front of the factory grounds, without caring about the protests or resistance of the local residents that have been showing in various ways. These and other examples provide opportunities for exploring how they have been able to negotiate with the factory and the local communities, and for exploring the mechanisms and processes that the workers have been able to use in those negotiations. Issues such as these are among the main reasons why the authors chose to study these particular Migrant workers at this particular site. In doing so, the authors employ the concepts of Michel de Certeau concerning the practices of everyday life as the primary framework for analysis.

\section{METHODS}

The scope of this study is limited to Myanmar migrant workers who are working in the Sidhiphatra Cold Storage Factory. The authors employed primarily qualitative methods, and more specifically drew on anthropological methodologies. The authors conducted fieldwork by conducting non-participative observations in various events organized by the people studied. The authors also conducted structured in-depth interviews, employing an interview instrument that the authors had constructed themselves in light of their review of relevant documents and research reports. In addition, the authors led focus group discussions.

In analyzing the tactics of negotiation used by these Myanmar migrant workers, the authors rely primarily on the concepts of the "tactics of everyday 
life" that were developed by Michel de Certeau. De Certeau (1988) divided practices into two major groups: (1) strategies; and (2) tactics.

"Strategies" in the meaning used by de Certeau, are places and institutions controlled by those- such as businessmen, the military, and cities-who have power and who are therefore able to manage or shape the activities of other groups, such as customers or competitors, enemies, or the rural areas surrounding the cities. In this particular case, the powerful actors who employ strategies of place and space are the owners of the Sidhiphatra Cold Storage Factory and also the Thai people of the area with whom Myanmar migrant workers must interact. The study therefore seeks to identify the strategies used to discourage, deprive, or control the Myanmar migrant workers to work in this area.

"Tactics" in the meaning used by de Certeau, are in some ways the opposite of strategies, in the sense that they are spaces created or used by "the other" and are arts or techniques used by the weak. For example, wars that are waged against people who have relatively little power are nevertheless infiltrated with a distribution of power into the place that is controlled or dominated by the powerful in ways that cannot easily be observed by outsiders. The weaker parties in the present study are the Myanmar migrant workers in the factory. Therefore, in this study, the authors are seeking answers to the following question: In seeking to achieve their objectives as the weaker party, what tactics have the Myanmar migrant workers used in their negotiations of daily life as they interact with various other groups within the strategies, or systems, established and managed by those who are more powerful than them?

\section{RESULTS}

In this study, the authors have discovered two sets of tactics of negotiation that the Myanmar migrant workers have used. One set of tactics has to do with negotiations with the factory as an institution. The other set of tactics has to do with negotiations with the Thai communities and individuals surrounding the factory.

\section{Negotiations With the Factory-Being "Selected" or Favored Workers}

The Myanmar migrant workers in this factory have displayed behaviors that have functioned as "tactics" that caused the factory to continue employing them.

Respecting the factory's rules and regulations. Most of the Myanmar migrant workers who are employed in the Sidhiphatra Cold Storage Factory work in the areas of manufacturing production. This work includes such things as weighing the fish, sorting the fish, and cleaning the fish. The section that has the most employees is the department where the employees scrape the scales from the fish. Most of the workers are employed in two shifts. The day shift is 8:00 am to $5: 00 \mathrm{pm}$ and the night shift is normally 7:00 pm to 4:00 am. The exact hours depend on the schedules established by the human resources department. All of the employees from Myanmar were hired by means of a Memorandum of Understanding (MOU). The Sidhiphatra Cold Storage Factory employs Myanmar migrant workers by means of contracts of six months' duration. If an employee displays inappropriate behaviors or violates the terms of the contract, the factory is authorized to request a replacement for the employee. Because of these provisions, the employees live in great fear of being sent back home. Therefore, they go to great lengths to keep quarrels, fighting, and conflicts to a minimum. Mr. R Zar Ni, translator and supervisor of the workers' housing, reported as follows:

There is very little problem of workers fighting. Those incidents that do occur are mostly small conflicts over little things. Whenever a major problem arises, the workers involved are immediately dismissed. The workers are afraid, and they rarely fight among themselves. If they do, they had better not let the human resources department know about it. 
(R Zar Ni, personal communication, 21 July, 2016)

The factory has two departments that look after the behavior of the workers. One of them is the department in charge of the workers' residences. $\mathrm{R}$ Zar Ni and the head of the workers' residences are jointly responsible, and if there are any incidents that the housing staff cannot resolve on their own, they report the incident to the head of the human resources department. The human resources department will then have the labor relations department been responsible for dealing with the problem. $\mathrm{R}$ Zar Ni reported that, for the most part, if the quarrels progressed to the level of using weapons, or if there were incidents of drinking intoxicating beverages within the factory, the persons responsible will definitely be dismissed. The employees therefore are very afraid of these rules. Consequently, the factory employees need to show strict adherence to the factory's rules and regulations so that the factory will not send them back home. Despite this, the Myanmar migrant workers in this factory have been able to show some negotiating power in response to the employers, namely, through their demonstration of the role of good employees who work hard, have stamina, and show good responsibility for their work, so that their employers will accept them and continue to employ them instead of sending them back to their home country. They therefore display an attitude of deference and humility, along with strict adherence to the factory's rules and regulations.

Showing oneself to be a hardworking employee. The Sidhiphatra Cold Storage Factory has worked to stimulate the morale of the workers by having the manufacturing production department kept records and given points to the employees who work the hardest each month. These employees are given an award which is called the "Reward for Excellence in Removing Fish Scales". The reason the award has this name is because the fish scaling department needs more workers than the other departments. The reason for this is because the removal of fish scales and skins requires mostly manual labor. The process cannot be mechanized, because the removal of fish scales and skins requires very careful and precise work. Therefore, the factory created this award to boost the morale and effort of the employees who are skilled at removing fish skins cleanly and quickly. Each month, three employees who are hardworking and highly skilled receive awards, namely, the first-place, second-place, and third-place awards. In addition, every year, there is recognition of the employees who received the highest scores in their production divisions. For example, one award goes to the employee who received the first prize in fish scaling for three months, which is the highest score in the factory. This person will be selected to be recognized as the best fish scaler of the year. Other, lesser awards are also given in accordance with the statistics that have been accumulated. These awards have greatly stimulated the efforts of Myanmar workers. Thai workers rarely win these awards, due to the greater industriousness of the Myanmar migrant workers.

Negotiating to remain employed in the aftermath of conflicts with workers from Cambodia. The value of the above tactics became especially apparent. In the year 2013, there arose conflicts between the Myanmar workers and the Cambodian workers who were also employed at the time. Prior to that point, ever since the factory had been established in 2005, the factory had been hiring migrant workers from both of these countries by means of MOU arrangements, with the greater proportion of workers coming from Myanmar. In the year 2013, conflicts between the two nationalities became so great that there was an outbreak of violence that resulted in one death from each nationality. Since the factory was no longer able to hire workers from both countries, it decided from that point forward to hire only workers from Myanmar, since they already comprised the greater part of the work force and already had stronger and more stable leaders. An additional reason that the 
factory gave for preferring the Myanmar workers over the Cambodian ones was that the Myanmar workers were harder workers and showed greater patience and stamina. Mr. Phaithoon, a Thai employee of the factory, provided the following information:

In the end, the factory chose to hire only people from Myanmar, and they completely stopped hiring Cambodians. This was probably because the factory had to reconcile with the Myanmar workers, since there were more of them, their team leaders were better, and they were more skillful. I don't exactly know how their leaders negotiated with the factory. But the Cambodians must have had less negotiating power. What I mean to say is that the factory had to choose between the workers from Myanmar and the ones from Cambodia. They could not hire from both groups. So the factory had to choose between the groups. And there is another thing. They said that the employees from Myanmar were harder workers than the ones from Cambodia. They were sturdier, could tolerate greater workloads, would work late at night, and would work hard to get the work done. I myself had noticed that the Cambodian workers rarely worked overtime, but most of the workers from Myanmar were willing to do so. (Phaithoon, personal communication, 30 June, 2016)

Drawing on the conceptions of de Certeau, we can say that the workers from Myanmar used important "tactics" in negotiating with the employers by taking on the role of exemplary employees. Because they had been displaying their good points of being employees who are hard workers, who are committed to their tasks, and who respect the rules and regulations of the factory, this caused the factory to decide to hire them instead of hiring the Cambodians. It can be seen that "tactics" like these are the opposite of the "strategies", in that they involve the spaces and actions of those who have lesser power. In the present study, the people of lesser power are the Myanmar migrant workers. Their actions in this case are like the ones that de Certeau described as struggles in which the people with lesser power infiltrate or interpenetrate their interests back into the areas dominated by the strategies of the powerful, due to the distribution of power into the spaces controlled by those with power, albeit doing so in ways not easily observed. De Certeau referred to "tactics" such as these as "mechanisms of lesser power that the weak have used in encountering the powerful".

Thus, in this study, "strategies" refer to the rules and regulations established by the factory in order to control the Myanmar migrant workers, while "tactics" show the role of the Myanmar laborers as they adhere to the factory's regulations and also as they avoid some of those regulations to the extent that the situation allows. The workers realize that they are not in a position to specify "strategies" on their own, and they therefore try only to seize those opportunities and objectives that they are actually able to do. Examples of this that can be clearly seen include the establishment of ethnic group committees to intermediate between the various ethnic groups and the factory by passing along to the factory the requests and negotiating points of the workers. These include concerns about benefits and wages that the workers should receive. For example, in the year that the government of Prime Minister Yingluck Shinawatra implemented the policy of the 300 baht per day minimum wage, the core leaders of these committees joined together in discussions with the human resources department, and in these discussions, they successfully negotiated to have the new minimum wage rates applied to the Myanmar migrant workers. In addition, they called for the payment of extra wages for overtime work. Previously, the factory had not provided extra pay for the extra hours, but had only provided the basic daily wage, no matter how many hours were worked, and this had caused such dissatisfaction among the workers that there arose a group of core leaders to represent the workers in demanding overtime wages for all workers, with no exception. In addition, the ethnic group committees were representatives of the groups in coordinating or solving problems within the factory. The problems that arose in the course of work or the performance of duties within the factory could be problems between 
the workers and the factory, or between the Myanmar migrant workers and the Thai workers, or problems among the Myanmar workers themselves. The representatives or ethnic group committee members would attempt to mediate or solve the problems that arose.

\section{Negotiations With the Communities and the Individual Thai People in the Area}

In addition to the "tactics" that they used to remain employed by the factory, the study also revealed that the workers from Myanmar also used "tactics" for negotiation with the Thai people who lived in the area. These people differed from the Myanmar workers both in culture, language, and especially religion, as the local residents were mostly Muslims who were very strict in their religious observance. The local religious leaders played especially important roles in establishing the rules to be applied in managing the Myanmar workers who had come to work in this area. In this section, it will be shown that the community leaders, the local governmental leaders, and the religious leaders can be conceived as the group that used "strategies" that employed power in the sense of de Certeau. Tha Samlee Subdistrict, where the factory was located, is an area inhabited by Muslims, and they are the group who in this case had greater power to determine or manage the situation of the weaker parties. Specifically, in dealing with the Myanmar migrant workers to live in Tha Samlee Subdistrict, "strategies" were applied with the intent of separating the local communities, their power, and their desires away from the workers. "Strategies" in this case, are activities of power that have a clearly visible base or stronghold, and they determine the terms of relationships with other things that lie within their scope and radius. Therefore, in the present analysis, the local community leaders, the leaders of local administrative agencies, and the religious leaders, together with the individual Thai people of the locality, should be seen as setting the "strategies", as they collectively have "ownership" of the place where the migrant workers must interact with them. The study found that they have used a particular set of strategies to limit, control, or manage the Myanmar migrant workers who have come to work there. These strategies may collectively be called "The Imposition of Rules by the Community". Some 10 years earlier, when the Sidhiphatra Cold Storage Factory was being established, the managers of the factory came into Tha Samlee community to request permission to build the factory, hoping to coordinate with the community leaders, the heads of local government administrative organizations, and religious leaders to be able to do so. However, the proposal received stiff opposition from the local populace, because they had concerns about the security and safety of their communities. They feared that the workers from abroad who came to work in Tha Samlee Subdistrict would create problems and trouble for the local people, so they proposed the following three basic agreements to the factory:

(1) The Myanmar migrant workers would reside only within the factory area. They would be confined to the work spaces and the living quarters provided by the factory, without being allowed to have anything to do with the area outside the factory. This meant that the workers had to stay within the factory grounds 24 hours a day;

(2) Prohibitions were placed on the opening of entertainment establishments such as pubs, karaoke bars, and liquor stores. Also, the sale of whiskey and alcoholic beverages was to be prohibited both in the factory and in nearby areas, because the population of Tha Samlee Subdistrict was $90 \%$ Muslims, and the local residents were fairly strict in their religious observance. Therefore, they were not willing to allow alcoholic beverages to be sold in the area;

(3) It was strictly forbidden to sell pork both within the factory and in the area near the factory, because this was an area inhabited by Muslims, and it was known that Muslims do not eat pork. However, 
most of the laborers who were coming to work at this factory were from Myanmar, and the primary group were Buddhists who were in the habit of eating pork and who preferred to cook their own meals. At one point, two female merchants from elsewhere came to set up fresh pork stalls in the fresh market in front of the factory. But they were able to sell for only a few days before the Muslim villagers of the area complained to the community leaders and religious leaders. The result was that the vendors were not allowed to sell pork directly in that area.

By the time of this study, the Myanmar migrant workers had been able to negotiate successfully with the local community on two of the above points. The first point is that the Myanmar migrant workers are now free to travel outside the factory grounds, and they are also able to rent housing outside the factory. They are also able to drink alcoholic beverages and go frequently to entertainment establishments in the area in front of the factory, without the factory being able to stop them. The reason given by the factory is that the drinking of alcohol and the use of entertainment establishments are happening outside the factory grounds. Furthermore, these activities are having no negative effects on work inside factory. In addition, the Myanmar migrant workers were gathering to drink liquor in front of the factory, arguing that this was ok because they were not drinking inside the factory at all. It can be argued, therefore, that the drinking of alcohol in front of the factory by the Myanmar migrant workers is an example of the devices that the workers have inserted into the area of power, the tactics of survival that they are secreting into the various activities being done in order to gain them the benefit of being able to relax after they have finished working.

It can therefore be seen that the Myanmar migrant workers in this factory have used a variety of "tactics" to survive, to improve their quality of life, and to evade some of the rules and regulations that had been imposed by the community. The members of the local community are not able to completely control the Myanmar migrant workers, because this particular group of workers has been able to draw on certain negotiation tactics that enable them to live harmoniously with the local community. Nevertheless, although the Myanmar migrant workers have been able to successfully negotiate some of these issues, they have not successfully negotiated to be able to buy fresh pork from vendor stalls in the market in front of the factory. This is the only one of the above issues that they have not yet been able to negotiate. It is possible that their negotiations on this issue may be successful in the future. However, at the time, in the present study, the authors found that on this issue the Myanmar migrant workers have been unable to bargain or negotiate with the strong religious faith of the people of Tha Samlee Subdistrict, which has so many Muslim residents.

Another tactic that the Myanmar migrant workers are using to be able to live together with the people of the area is that they are trying to adapt in the area of language, because the ability to communicate is one of the things that will ease their interactions with the local Thai people. In addition to needing to learn the official version of the Thai language, they also need to learn the local Southern dialects. Most of the Myanmar migrant workers try to learn as much of the Thai language as they can, because every day they have interactions with Thai people, especially when buying things at the fresh market and when traveling around to take care of various errands.

In addition, the Myanmar migrant workers have been working to foster greater acceptance in the community by participating in various community activities and events, including events sponsored by Tha Samlee Subdistrict municipality. For example, a young woman from among the Myanmar migrant workers is representative of the Sidhiphatra Cold Storage Factory in the Full Moon Angel beauty queen contest, in which they compete alongside Thai contestants during the Loy Krathong festival 
sponsored by the municipality. In this contest, the factory does not really expect to win. However, it desires that its Myanmar migrant workers participate in activities together with Thai people and hopes that as a result, the Thai people of the area will reduce their opposition and bias against the Myanmar migrant workers. Therefore, the hope for a prize or award for the Myanmese contestants is not the main objective of the factory. In addition, the factory encourages the Myanmar workers to join in the various community activities such as temple development projects, mosque development projects, merit-making festivals on important occasions such as the offering of robes to monk, and various other charitable activities such as planting mangrove forests, transporting sand to mountain-top temples, and so on. These activities have caused the Thai people of the area to reduce their bias against Myanmar migrant workers. In addition, these activities have caused Myanmar migrant workers to feel that they are part of this community. Even though they had not been born here nor grown up here, yet they are residing here and pursuing their occupations here. Therefore, if there are any activities that they can help or participate in, they are happy to do so.

\section{DISCUSSION}

In regards to this point, one of the most interesting findings of this study is that the Myanmar migrant workers in the Sidhiphatra Cold Storage Factory are negotiating in new ways. One of the things they are negotiating is the meaning of the phrase "Who do we Myanmar migrant workers belong to?". In other words, they are not merely typical Myanmar migrant workers. Rather, they are Myanmar migrant workers who have a special connection with a person of importance, because the owner of the factory has been a benefactor towards the community, a person who has social charisma, and a person who is well-known by the people of Songkhla. Consequently, this group of Myanmar migrant workers is perceived as having an "owner", and their perceived special association with him is important in itself. Therefore, even though the people of the local area had been relatively biased against the Myanmar migrant workers, for example assuming that they would bring trouble to the community and that they would drink alcohol and drive motorcycles without regard to the traffic rules, yet the villagers were not able to insist on the strict implementation of their preferred rules, because of their respectful concern for the owner of the factory. The villagers also accepted that the opening of this factory in their community had brought greater prosperity to their community. The factory owner's role in fostering this greater prosperity could be seen in many ways. For example, the factory owner was supporting the budget for expanding community infrastructure, including improvements in the area of education and in the area of sports facilities for the community's children. In addition, the factory owner was supporting religious activities and charitable endeavors.

Therefore, the Myanmar migrant workers at the Sidhiphatra Cold Storage Factory have not just been creating spaces for negotiation with the area's Thai people through linguistic adaptation and community participation. They have also been creating spaces for negotiation with Thai people by causing themselves to be more respected by the local Thai people than is often the case with Myanmar migrant workers in other places. Therefore, one of the key findings of this research project is that the Myanmar migrant workers are able to smooth relationships with the surrounding communities by using the tactic of being Myanmar migrant workers associated with an important person, namely the head of the factory's administrative board, who has been building patronage connections with the local Thai communities. These relationships have been conducted with increasing facility and ease, because this person is a local politician with a great deal of power and influence in Songkhla province. As 
noted above, this person is not only powerful but also has charisma. Consequently, being an employee or person related to him gives the Myanmar employees increased social standing. It is also a new phenomenon, for these Myanmar migrant workers are not just ordinary workers; rather, they are workers connected with an important person in Songkhla province. Consequently, the Myanmar migrant workers in this factory are able to use their relationship as subordinates of this factory owner as an important tactic in negotiating with the Thai people of the area in order to reduce the bias that has developed.

\section{CONCLUSIONS}

The above study has shown that when we apply de Certeau's framework to the various kinds of power that arise in the relationships among the factory, the workers, and the local communities, those expressions of power can be divided into two groups - strategies and tactics: (1) Strategies are the places occupied by the side that has power and that is therefore able to manage the others. In the present study, it can be seen that relative power is in the hands of the Sidhiphatra Cold Storage Factory and in the hands of the local Thai people and communities with whom the Myanmar migrant workers must interact. The rules imposed by the factory and by the local communities can therefore be considered "strategies" to limit and control the Myanmar migrant workers and to get them to give in to power; and (2) tactics are the places of the others, or of the weak. In this study, the "weak" are the Myanmar migrant workers who work in this factory. De Certeau's treatment seeks to show that the powerful are not able to control all aspects of everyday life. Accordingly, de Certeau is interested in exploring the ways that the weaker or dominated parties identify and use the openings and opportunities that they are able to find within these systems of the powerful in order to obtain benefits despite the systems are imposed by those who are more powerful.
In de Certeau's view, the practices of daily life have to do with the contestation and negotiation of power relations between those who impose systems and those who live within them. Overall, this has to do with more than just relationships. Rather, it has to do with the circuits of power that move continuously through daily life. De Certeau's thought has the objective of showing that "power" cannot entirely control "everyday life". We have seen this through the resistances to power shown by the Myanmar migrant workers as they negotiated with the rules and regulations of the factory and of the local communities. Some of these efforts have succeeded, while others have not. In the authors' view, similar phenomena are likely to be found among other groups of Myanmar migrant workers in other provinces or in other places. Studies of Myanmar migrant workers in other places should give similar attention to the negotiation tactics used by the weaker parties. The authors suspect that these negotiations will display themselves in different ways as contexts vary from place to place.

\section{Acknowledgments}

The authors wish to thank the Office of Higher Education Commission for its assistance in conducting this research project.

\section{References}

Appadurai, A. 1996. Modernity at Large: Cultural Dimensions of Globalization. Minnesota: The University of Minnesota Press.

- 2001. Globalization. Durham and London: Duke University Press.

Basch, L., N. G. Schiller, and C. S. Blanc. 1994. Nations Unbound: Transnational Projects, Postcolonial Predicaments and Territorialized Nation-State. Amsterdam: Gordon and Breach.

Boonprakan, K. 2008. "Daily Life Action Practices of Border Muslim Merchants of PaDangPe Sa Thai-Malaysia." Ph.D. dissertation, Thai Studies, Mahasarakam University.

Cohen, R. 2006. Migration and Its Enemies: Global Capital, Migrant Labour and the Nation-State. Padstow, Cornwall: TJ International Ltd. 
de Certeau, M. 1988. The Practice of Everyday Life. Translated by S. F. Rendall. Los Angeles: University of California Press.

Kanchanapan, A. and C. Samniang. 2014. Transnational Labor, Identity and Citizen Rights. Chiang Mai: Institution of Public Policy, Chiang Mai University.

Koonpon, S. 2007. "Title of Everyday Life." Political Science Journal 28(2):113-146.

Lionnet, F. and S. Shumei. 2005. Minor Transnationalism. Durham and London: Duke University Press.

Ritzer, G. 2007. The Blackwell Companion to Globalization. Oxford: Blackwell.

Short, J. R. and Y.-H. Kim. 1999. Globalization and the City.
New York: Addison Wesley.

\section{Bios}

Phennapha Chandaeng, Ph.D. student of Asian Studies, School of Liberal Arts, Walailak University, Thailand; research fields: public administration, human resource management, Southeast Asian studies.

Jitprapat Saisopa, Ph.D., lecturer of Ph.D. curriculum of Asian Studies, School of Liberal Arts, Walailak University, Thailand; research fields: public administration, public policy, political sciences. 